\title{
Seismic reflection imaging of deep crustal structures via reverse time migration using offshore wide-angle seismic data on the eastern margin of the Sea of Japan
}

\author{
Kazuya Shiraishi* ${ }^{*}$, Tetsuo No and Gou Fujie
}

\begin{abstract}
We applied reverse time migration (RTM) to offshore wide-angle seismic data acquired with airgun shots and sparsely deployed ocean bottom seismographs (OBSs) for reflection imaging of the Moho discontinuity in the eastern margin of the Sea of Japan. While seismic tomography is generally applied to wide-angle seismic data for estimating regional velocity, reflection imaging is uncommon due to the low folds from wide-spacing OBS deployment. The long offset reflection data obtained by airgun-OBS surveys are promising for profiling deep crustal structures, which may be able to add constraints on the velocity structures estimated by tomographic inversion. Furthermore, reflection imaging from wide-angle seismic data is useful when only airgun-OBS data are acquired without any MCS data due to weather conditions or restrictions of using streamer cables. In this study, we validated the feasibility of RTM, which is an effective reflection imaging method based on wavefield modelling with the two-way wave equation, using offshore wideangle seismic data acquired along two crossing survey lines off Niigata-Yamagata. Airgun shot intervals were $200 \mathrm{~m}$ in both surveys, and the OBS spacings were $5 \mathrm{~km}$ along a 297-km-long line and $8 \mathrm{~km}$ or $16 \mathrm{~km}$ along a 366-km-long line, except for OBSs near the coast. By applying RTM with velocity models estimated by traveltime tomography of the same OBS data, we successfully imaged clear reflections around depths of 20-30 km. We confirmed that reflections observed in the long offset range were effective in imaging the deep structures that were not imaged by the MCS survey in this region. The depths of reflectors were traced from approximately $20 \mathrm{~km}$ in the offshore area to approximately $30 \mathrm{~km}$ near the coast, which corresponds to the Moho discontinuity. The depth variation is consistent with the crustal classification that was inferred based on tomography analyses: thick oceanic crust in the Yamato Basin and rifted continental or island arc crust beneath the areas from the Sado Ridge to the coast. Our results from two surveys with different OBS spacings suggested the high potential of the application to a wide variety of wide-angle seismic data for crustal-scale seismic exploration.
\end{abstract}

Keywords: Wide-angle seismic data, Reflection imaging, Reverse time migration, Deep crustal structure, Moho discontinuity, Sea of Japan

\footnotetext{
*Correspondence: kshiraishi@jamstec.go.jp

Research Institute for Marine Geodynamics, Japan Agency for Marine-

Earth Science and Technology (JAMSTEC), Yokohama, Japan
} 


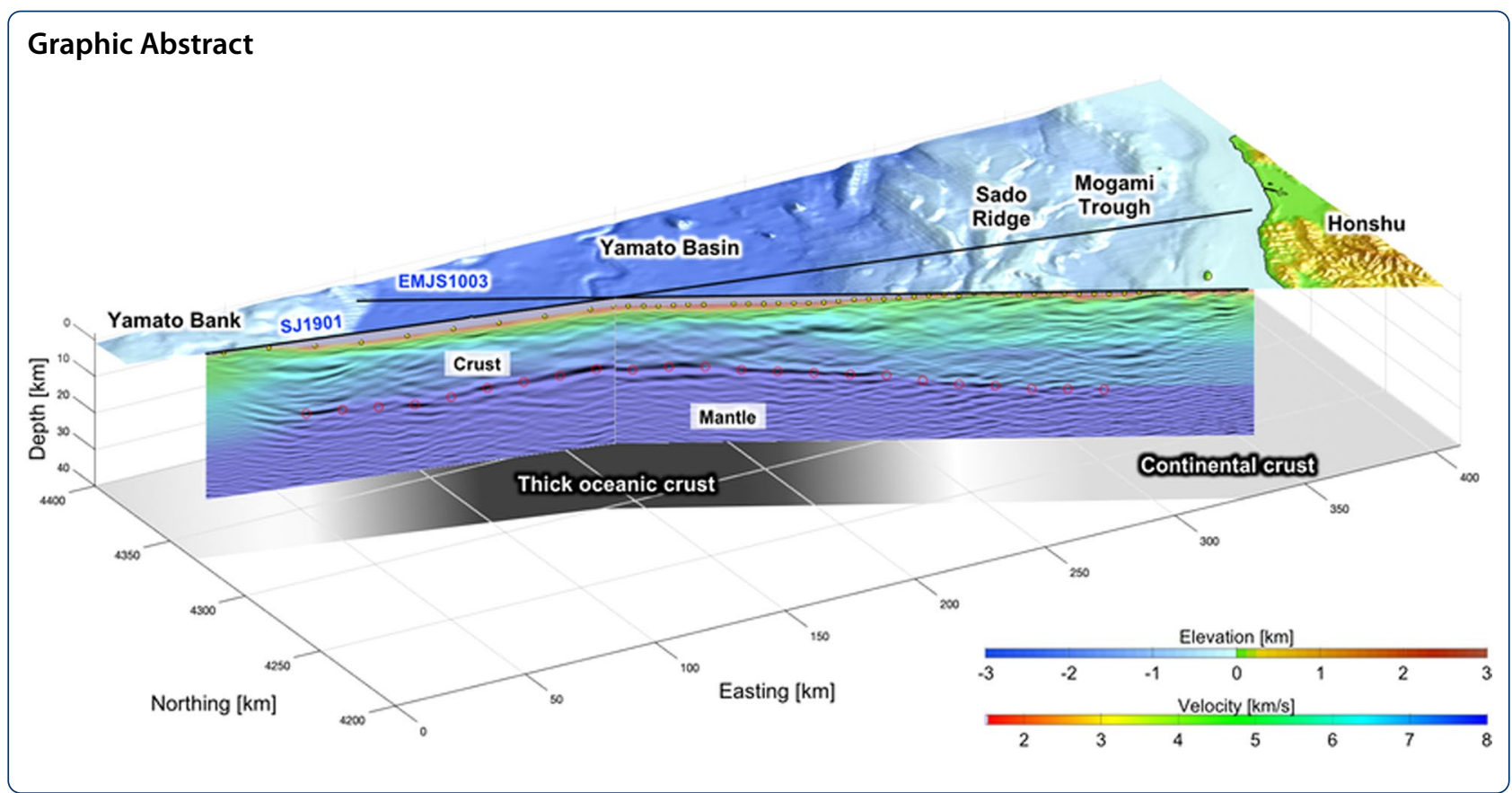

\section{Introduction}

In crustal-scale offshore seismic exploration, regional seismic velocity is generally estimated by traveltime tomography and waveform inversion using wide-angle seismic data acquired with airgun shots and ocean bottom seismographs (OBSs) (e.g., Nakanishi et al. 2008; Kamei et al. 2012; Górszczyk et al. 2017). Reflection imaging from airgun-OBS data is not common due to low folds in most cases of OBS deployment with wide spacing. Although detailed subsurface structures are imaged with high-resolution reflection profiles in multichannel seismic (MCS) surveys, imaging deep structures is still challenging due to the limited length of streamer cables. Reflections observed in the long offset range of airgun-OBS data are promising for containing information from deep structures, such as the Moho discontinuity, and they may add reflection boundary constraints on the velocity structures estimated by tomographic inversion from wide-angle seismic data (e.g., Zelt et al. 1998; Dessa et al. 2004; Qin et al. 2020). The traveltime mapping method (Fujie et al. 2006) is another technique to draw reflection boundaries using interpreted traveltime (e.g., Sato et al. 2014). This method requires prior manual phase picking on the OBS records, and the mapping result highly depends on the prior interpretation. In some situations with limited survey periods, only airgun-OBS data are available without any MCS data due to the following reasons: weather conditions, restrictions of using streamer cables by fisheries or marine traffic in survey areas. To overcome these problems, subsurface imaging by directly using reflections recorded in airgun-OBS data is important. In most cases of crustal-scale seismic exploration using OBSs with wide spacings of more than a few kilometres, not only reflection imaging by using primary reflections (Dessa et al. 2004; Qin et al. 2020) but also using multiple reflections by mirror imaging (Grion et al. 2007) and interferometric imaging (Shiraishi et al. 2017) are useful methods for obtaining reflection profiles, including shallow subsurface profiles, from nondense OBS data to better understand crustal structures in addition to detailed profiles by MCS surveys.

Reverse time migration (RTM) is an effective method for seismic reflection imaging based on numerical wavefield modelling with the two-way wave equation (e.g., Baysal et al. 1983; Chang and McMechan 1990). This method is now widely used for better imaging in complex models than conventional ray-based seismic migration methods (e.g., Etgen et al. 2009; Zhou et al. 2018). In a crustal-scale study, Shiraishi et al. (2019) applied the RTM-based technique for using primary and multiple reflections observed by $1-\mathrm{km}$ spacing OBSs to investigate the subducting plate and internal structures of the accreted sediments in the Nankai Trough.

On the eastern margin of the Sea of Japan, to elucidate the crustal structure and fault systems for investigating earthquake and tsunami hazards, seismic reflection and refraction surveys using both OBSs and MCS systems were intensively conducted (e.g., No et al. 2014a, b, 2018; Sato et al. 2014, 2020). Although crustal variations in the Yamato Basin were inferred based on the crustal thickness 
and seismic velocity derived by traveltime tomography using wide-angle seismic data (Sato et al. 2014, 2020), reflection imaging of the deep Moho discontinuity was difficult by MCS surveys. To better image deep structures, reflection profiles from airgun-OBS data are important. In this study, we validate the feasibility of RTM-based imaging for primary reflections recorded with wide-spacing OBSs to image Moho discontinuities using airgun-OBS data acquired during two different survey cruises.

\section{Method}

RTM is based on numerical modelling with the wave equation to simulate forward wavefields from the source with a function and backward wavefields from receivers with observed seismic records (e.g., Chang and McMechan 1990). By adopting the source-receiver reciprocity on the relation between airgun shots and OBSs, the downgoing wavefields are extrapolated forward in time from OBS locations, and the upgoing wavefields are extrapolated backward in time from airgun shot locations (Shiraishi et al. 2019). The forward-extrapolated wavefield $F_{i}(t, \boldsymbol{x})$ is simulated forward in time $(t: 0 \rightarrow T)$ based on a scalar wave equation with a migration velocity $c(\boldsymbol{x})$ and a source function $s(t)$ from the $i$ th OBS location $\boldsymbol{x}_{O B S_{i}}(i=1,2,3, \ldots, M)$ :

$$
\left\{\frac{1}{c^{2}(\boldsymbol{x})} \frac{\partial^{2}}{\partial t^{2}}-\nabla^{2}\right\} F_{i}(t, \boldsymbol{x})=s(t) \delta\left(\boldsymbol{x}-\boldsymbol{x}_{O B S_{i}}\right) .
$$

Here, $x$ is a spatial coordinate vector in the model domain, and $\delta\left(\boldsymbol{x}-\boldsymbol{x}_{O B S_{i}}\right)$ is the Dirac delta function. The backward-extrapolated wavefield $B_{i}(t, \boldsymbol{x})$ is simulated backward in time $(t: T \rightarrow 0)$, i.e. reverse time, with seismic traces $D_{i, j}\left(t, \boldsymbol{x}_{\text {shot }}\right)$ of the $i$ th OBS record from airgun shot points $\boldsymbol{x}_{\text {shot }}(j=1,2,3, \ldots, N)$ :

$$
\left\{\frac{1}{c^{2}(\boldsymbol{x})} \frac{\partial^{2}}{\partial t^{2}}-\nabla^{2}\right\} B_{i}(t, \boldsymbol{x})=\sum_{j=1}^{N} D_{i, j}\left(t, \boldsymbol{x}_{\text {shot }}\right) .
$$

We implemented wavefield modelling with a finite difference (FD) method of the scalar wave equation.

Then, subsurface structures are imaged by time integration after correlating the two wavefields under imaging conditions (e.g., Claerbout 1971, 1985). The zero-lag imaging condition in the time domain is represented as:

$$
I(\boldsymbol{x})=\sum_{i=1}^{M} \int_{0}^{T} F_{i}(t, \boldsymbol{x}) B_{i}(t, \boldsymbol{x}) d t .
$$

Reflected waves illuminate the subsurface points $x$ in the model by the temporal integration of the product between the forward-extrapolated wavefield $F_{i}(t, \boldsymbol{x})$ and the backward-extrapolated wavefield $B_{i}(t, \boldsymbol{x})$ with respect to the $i$ th OBS record $(i=1,2, \ldots, M)$ at every time step from $t=0$ to the maximum time, $t=T$. Finally, we obtain the subsurface image by stacking the image sections from all OBS records.

\section{Data}

The wide-angle seismic data used in this study were acquired in the western offshore area of Niigata and Yamagata, Japan (Fig. 1a). The data were collected along two lines, EMJS1003 and SJ1901, in different surveys in 2010 and 2019, respectively. These two lines crossed each other at approximately $220 \mathrm{~km}$ offshore from the coastline. The water depth along the survey lines ranged from approximately $50 \mathrm{~m}$ near the coast to approximately $2660 \mathrm{~m}$ in the Yamato Basin. A tuned airgun array with a total volume of 7800 cubic inches $(128 \mathrm{~L})$ towed from $\mathrm{R} / \mathrm{V}$ Kairei was fired every $200 \mathrm{~m}$ at a depth of $10 \mathrm{~m}$ in both surveys. On the 297-km-long line of EMJS1003, 58 OBSs were deployed with $5 \mathrm{~km}$ spacing, which was a typical spacing for investigating regional velocity by traveltime tomography, and 57 OBSs were retrieved. An MCS survey was conducted along the same line of EMJS1003 with a $5.5-\mathrm{km}$-long hydrophone streamer cable of 444 receiver groups at $12.5-\mathrm{m}$ intervals, and the same airgun array fired every $50 \mathrm{~m}$. On the $366-\mathrm{km}$-long line of SJ1901, 39 OBSs were deployed and retrieved with variable spacings of $2 \mathrm{~km}, 8 \mathrm{~km}$, and $16 \mathrm{~km}$ from near the coast to the offshore area. Except for four OBSs near the coast, the originally planned spacing was $8 \mathrm{~km}$, but the actual deployment spacing in the offshore region was changed to $16 \mathrm{~km}$ during the survey to avoid the risk of a typhoon by reducing the working time. MCS data were not acquired on the same line of SJ1901 because of weather conditions in the limited survey period. In both airgun-OBS surveys, each OBS had three-component geophones and a hydrophone sensor. Moho reflections were clearly observed in most of the vertical component geophone records (Fig. 1b-d).

\section{Data processing and imaging}

We used the vertical component records followed by preprocessing. To generate a transfer function for minimum phase conversion, we extracted a basic waveform by stacking the shortest offset traces aligned at the first arrival time of OBS records for each survey line. After we conducted minimum phase conversion using the transfer function based on the extracted waveform to the OBS record, we applied gap deconvolution with a predictive distance of $0.04 \mathrm{~s}$ to enhance reflection signals by suppressing airgun bubble effects and shortperiod reverberations. Then, automatic gain control with a gate length of $3 \mathrm{~s}$, bandpass filter passing of $1-6 \mathrm{~Hz}$, and muting before the first arrivals were performed. The record length was limited to $20 \mathrm{~s}$ with a sampling interval of $0.005 \mathrm{~s}$ from $70 \mathrm{~s}$ or $80 \mathrm{~s}$ of the original records 

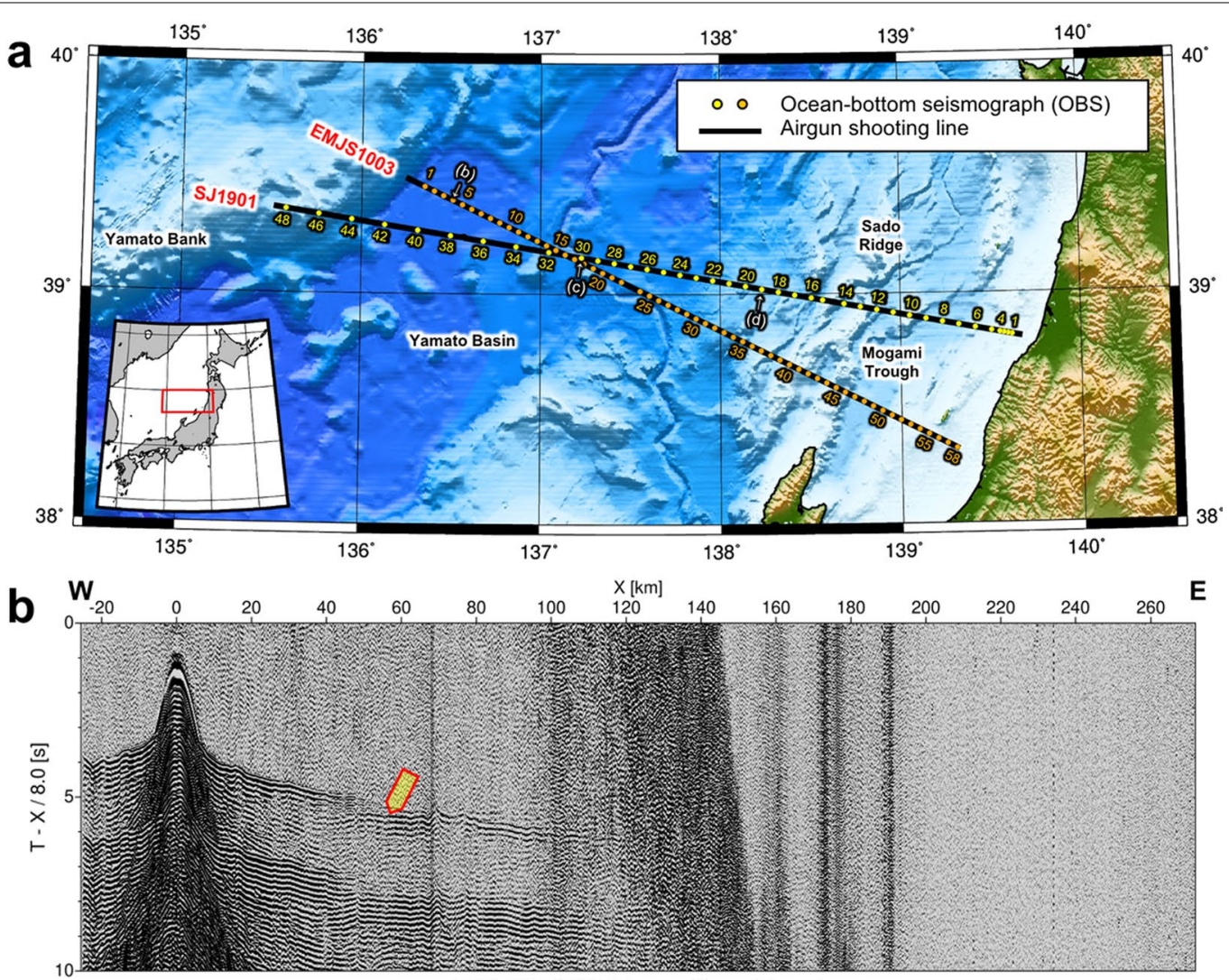

EMJS1003 / Location No. 4

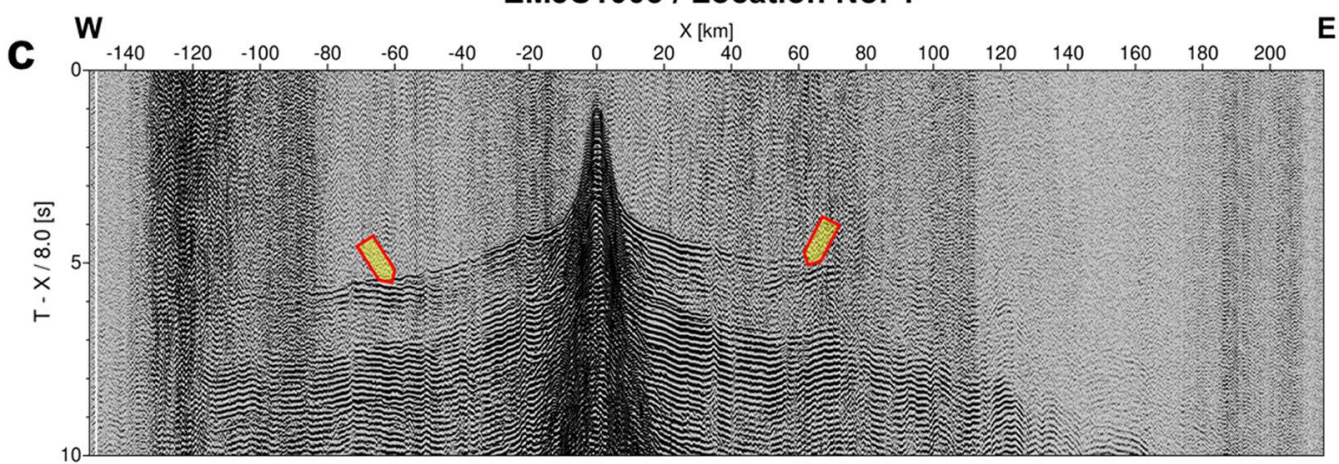

SJ1901 / Location No. 30

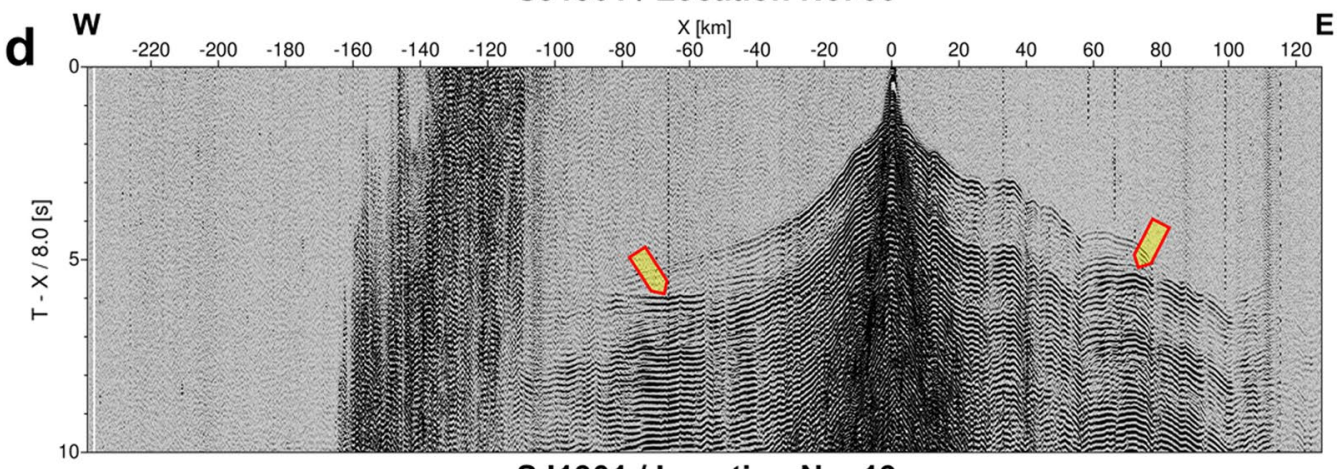

SJ1901 / Location No. 19

Fig. 1 Map of survey lines and examples of airgun-OBS survey data. a Two survey lines, EMJS1003 and SJ1901, are located off the western coast of Niigata and Yamagata, Japan. OBS records at b No. 4 along line EMJS1003, c No. 30 and d No. 19 along line SJ1901. Clear reflections from the Moho are visible in the recorded sections, which are indicated by yellow arrows 
for efficient computation. The source-receiver distance of input seismic records was limited to $100 \mathrm{~km}$ because most effective reflections from the Moho were observed at less than approximately $100 \mathrm{~km}$ of offset, and the data quality decreased in the farther offset range (Fig. 1b, c). An example of preprocessed OBS records with enhanced reflection signals is shown in Fig. 2a.
Regional velocity structures that were estimated by traveltime tomography using both the first arrivals and Moho reflections identified on the airgun-OBS data were available as the migration velocities for RTM for each line, EMJS1003 (Sato et al. 2014) and SJ1901 (No et al. 2020). We edited these models for feasible FD modelling. The models were gridded to $50 \mathrm{~m}$ in both the horizontal

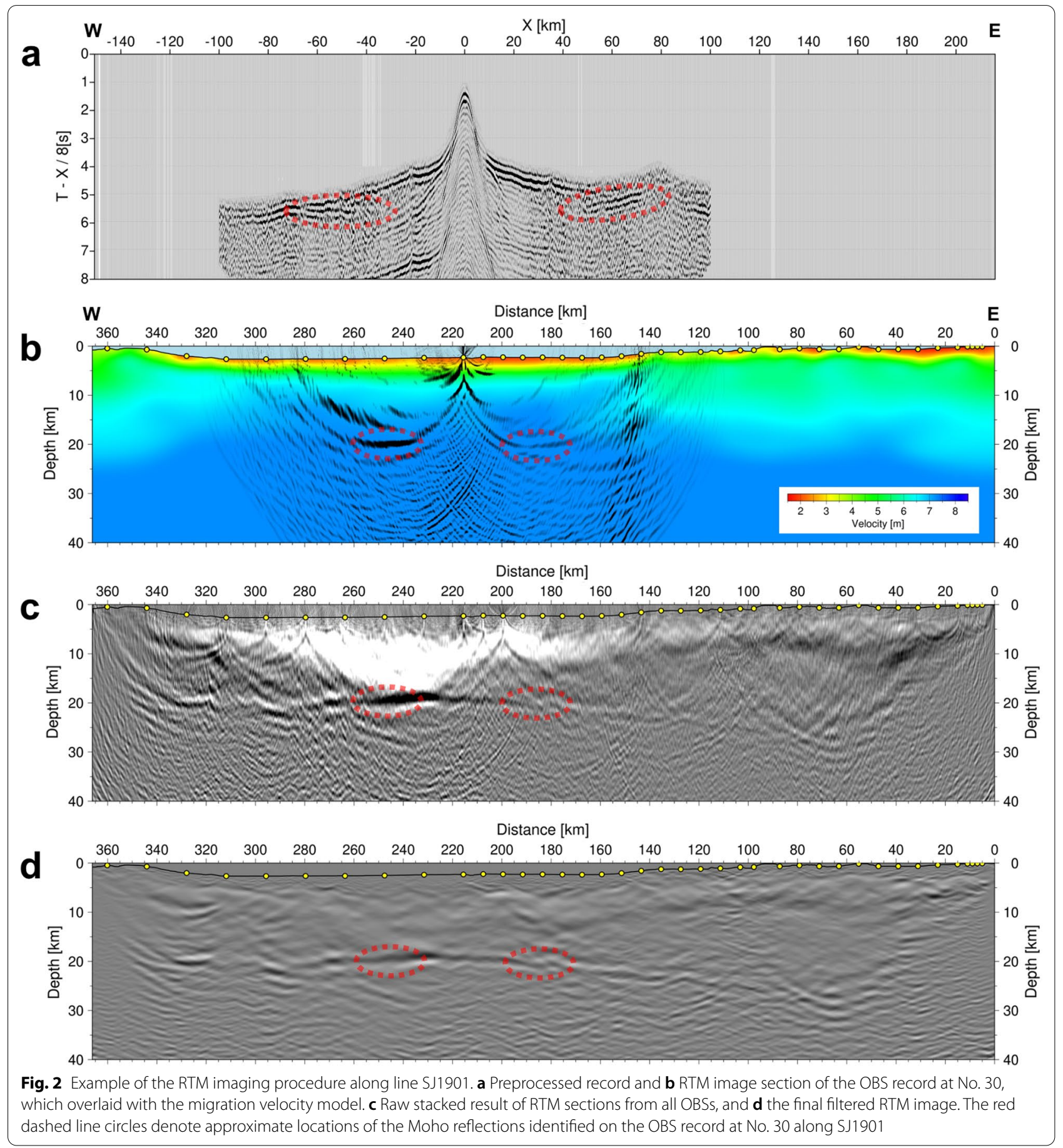


and vertical dimensions by setting the seafloor with the observed water depth, which was changed from the original grid size of $100 \mathrm{~m}$ used in the traveltime tomography. The maximum velocity was limited to $7.25 \mathrm{~km} / \mathrm{s}$, and spatial smoothing was applied to the models to avoid unexpected reflections and waveform stretching due to rapid velocity changes at the Moho and local velocity anomalies in the original tomography models. To use only upward reflections from subsurface boundaries, an absorbing boundary condition was used at the surrounding four boundaries of the velocity models, including the sea surface.

FD modelling for wavefield extrapolation was conducted with a time step of $0.0025 \mathrm{~s}$ and a total length of $20 \mathrm{~s}$. We used a zero-phase wavelet, the Ricker wavelet of $f_{\text {peak }}=4 \mathrm{~Hz}$, for stable computation of the forward extrapolation from OBS locations. In the backward extrapolation, the preprocessed waveforms were input from the airgun locations for wavefield modelling in the reverse temporal direction. We correlated the extrapolated wavefields from 0 to $20 \mathrm{~s}$ in time with a temporal interval of $0.005 \mathrm{~s}$. After stacking the migration sections from all OBS records (Fig. 2b, c), we applied a 2D wavenumber filter with a passing dip between -0.25 and 0.25 to eliminate artefacts caused by the sparse deployment of OBSs and a spatial bandpass filter of $0.03-10 \mathrm{~km}^{-1}$ in the vertical direction. After amplitude balancing in the horizontal direction based on smoothed root mean square (RMS) amplitude variation, the final reflection profiles were obtained (Fig. 2d).

The MCS data with 50-m shot intervals along EMJS1003 were processed with the conventional common midpoint stacking method, including noise and multiple suppression, deconvolution, velocity analysis, stacking traces after normal moveout, and poststack time migration (No et al. 2014b). The time migration image after applying a bandpass filter of $3-36 \mathrm{~Hz}$ was converted to the depth domain using the tomography velocity.

\section{Results and discussion}

We obtained reflection profiles that show continuous reflectors at depths of approximately $20-30 \mathrm{~km}$ (Figs. 3a and 4a), which correspond to the depth of the Moho discontinuity suggested by the velocity models (Figs. $3 \mathrm{~b}$ and $4 \mathrm{~b}$ ). In the reflection profile of EMJS1003 (Fig. 3a), the Moho discontinuity that is unclear in the MCS reflection profile (Fig. 3c) is visible in the RTM image from airgunOBS data. The wide-angle reflection data of the airgunOBS survey consist of lower frequency signals because of the decay of higher frequency components during wave propagation, and the processed frequency bands are different between the OBS data and MCS data. The lowfrequency energy of the wide-angle reflections is likely effective for imaging deep structures. Furthermore, primary reflections in the long offset range outside of multiple reflections illuminate the deep structures. These factors, low-frequency signals and long offset reflections, may be effective for better imaging than those of the MCS data with a limited-length streamer cable whose later reflection signals tend to be smeared by multiples and swell noise. We also successfully obtained a reflection profile that shows clear reflections at the Moho discontinuity in regions with $8 \mathrm{~km}$ and $16 \mathrm{~km}$ spacing between OBSs along line SJ1901 (Fig. 4a, b). In a threedimensional view of the RTM images and tomographic velocity on the crossing lines with the regional topography (Fig. 4c), the imaged Moho reflections and the velocity models almost correspond to each other at the crossing point, although the velocity models were analysed independently for two lines. The depth of the Moho reflections can be traced from approximately $20 \mathrm{~km}$ beneath the Yamato Basin to approximately $25-30 \mathrm{~km}$ near the coast through the Sado Ridge and the Mogami Trough. The depth variation imaged by the RTM is consistent with the crustal classification based on tomography analyses and traveltime mapping of airgun-OBS data, which suggests variation from thick oceanic crust in the Yamato Basin to rifted continental or island arc crust in the area beneath the Sado Ridge to the coast (Sato et al. 2014, 2020). The reflection profiles from the direct use of airgun-OBS data newly added evidential constraints of the Moho discontinuity to the velocity boundaries estimated by traveltime tomography.

To validate the velocities used for RTM, we compared RTM results obtained from different velocity models by limiting the maximum value and scaling of velocities from the base model (Fig. 5). Because of the low fold number in reflection imaging with wide-spacing OBSs, we are able to evaluate only stacked RTM images on the visibility and continuity of reflectors instead of migration gathers used in conventional evaluation in reflection imaging with MCS data. The comparison results show that the velocity obtained by traveltime tomography is not always optimal in RTM to illuminate reflections clearly at the Moho (Fig. 5b), and other models after limiting or scaling velocities can generate better RTM images (Fig. 5c-g). Based on the clear continuity of the Moho reflectors, we finally selected the velocity model limited up to $7.25 \mathrm{~km} / \mathrm{s}$ without rapid change at the possible Moho discontinuity (Fig. 5d). The velocity model with rapid change, which was obtained by ray-based traveltime tomography, could be inappropriate for the RTM that deals with finite-frequency waves. The focusing of reflections at the Moho may be decreased by waveform stretching and bending of wave paths by the rapid velocity increase that is at a shallower depth than the 

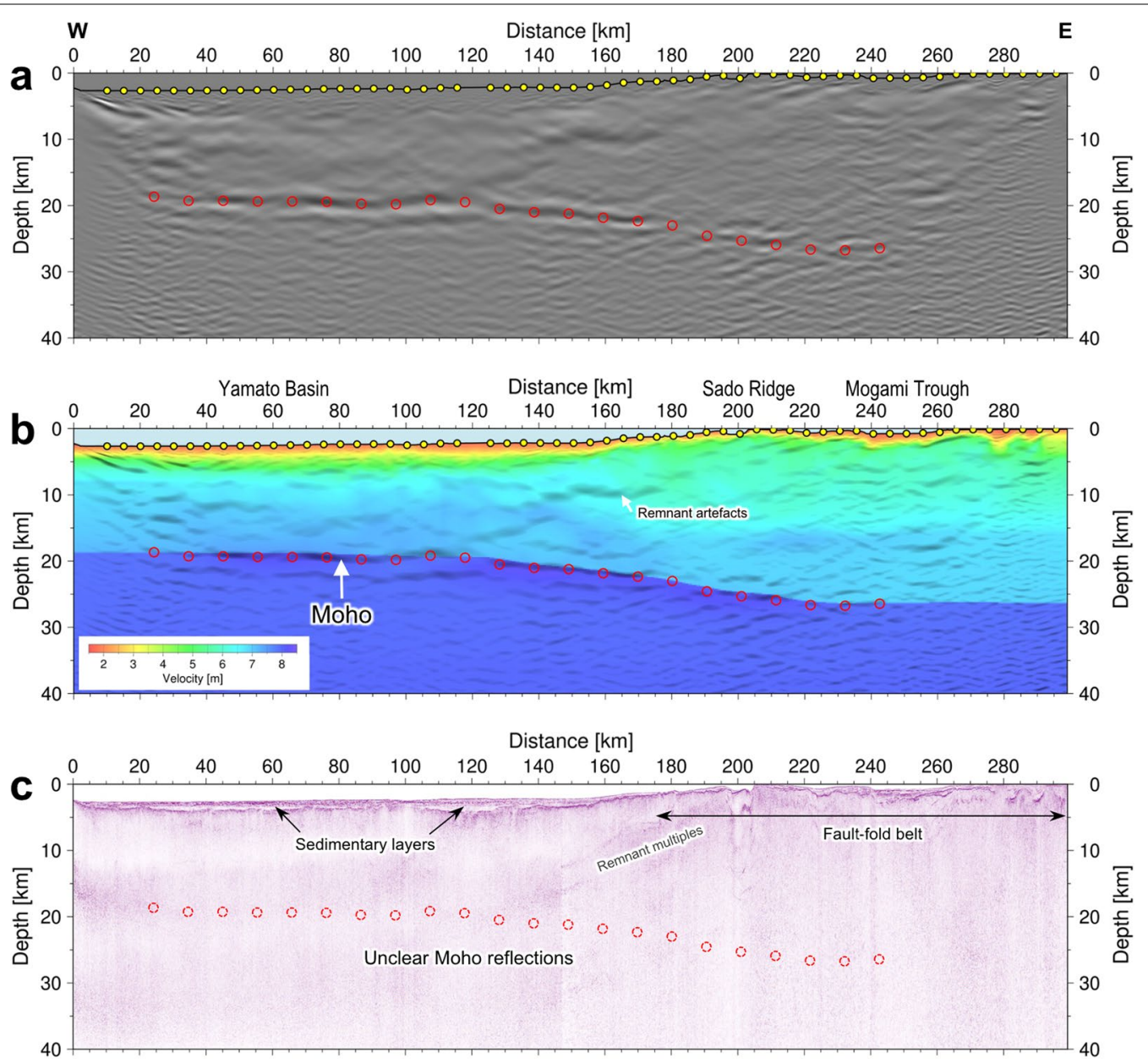

Fig. 3 Seismic profiles along line EMJS1003: a reflection profile obtained by RTM from airgun-OBS data in this study; $\mathbf{b}$ velocity model obtained by traveltime tomography (after Sato et al. 2014), and c depth-converted reflection profile of poststack migration from the multichannel seismic survey along the same line (after Sato et al. 2014). The yellow dots indicate OBS locations, and the red circles denote the probable Moho reflections

imaged reflector (Fig. 5d). Furthermore, even though the ratio of velocity scaling is a few percent, the cumulative velocity difference from the seafloor to the target depth may affect the focusing of reflections at the Moho boundary (Fig. 5f, g). The sensitivity to velocity structures could be high because of low folds of wide-angle data obtained with sparsely deployed OBSs. Uncertainties of the lower crust velocity and the Moho depth estimated by the traveltime tomography are not negligible in general (e.g., Korenaga et al. 2011; Sato et al. 2020). The discrepancy in velocity values and depth of the Moho between reflection imaging and traveltime tomography suggests the possibility of further improvement of the crustal structure model by combining the velocity and reflection profiles.

Consequently, we confirmed that RTM-based primary reflection imaging is feasible for imaging deep structures using offshore wide-angle seismic data acquired with nondense OBSs. The significant results from two lines with different OBS spacings offer high potential for a wide variety of applications in crustal-scale exploration. In addition to our example of the Moho geometry in the back-arc region, the deep geological architectures in the forearc region of the plate subduction zone (e.g., Nakanishi et al. 2009, 2018) or oceanic plateaus produced by large igneous provinces (e.g., Korenaga 2011) are challenging targets that should be investigated with offshore wide-angle seismic surveys and the proposed method.

On the other hand, imaging shallow structures, such as sedimentary layers in the Yamato Basin and deformations of the fault-fold belt in the Sado Ridge to the Mogami Trough (Sato et al. 2014), is difficult by using only primary reflections because of spatial aliasing of migrated reflections from wide-spacing OBSs (e.g., Zelt et al. 1998). RTM with surface-related multiples (e.g., Grion et al. 2007; Liu et al. 2011; Shiraishi et al. 2017, 2019) could be useful for imaging internal structures of 

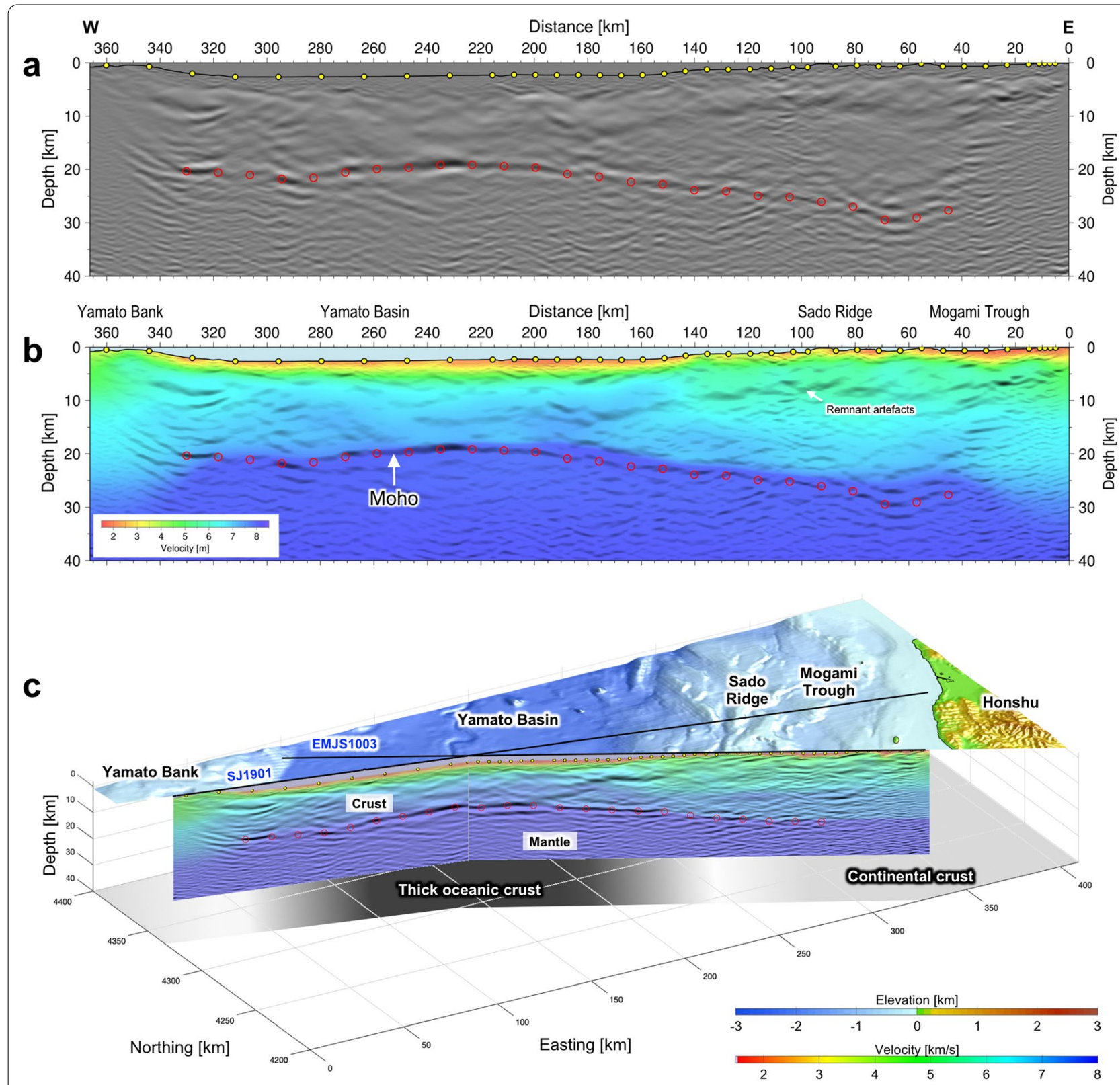

Fig. 4 Seismic profiles along line SJ1901: a reflection profile obtained by RTM from airgun-OBS data in this study and $\mathbf{b}$ velocity model obtained by traveltime tomography (after No et al. 2020). c 3D view of compiled seismic profiles of RTM images overlaid by tomography velocities along the two crossed lines with bathymetry. The crust varies from the thick oceanic crust beneath the Yamato Basin to the continental crust beneath Honshu Island, which was classified by Sato et al. $(2014,2020)$. The yellow dots indicate OBS locations, and the red circles denote the probable Moho reflections

the thick crust and sedimentary layers. Updating velocity models by waveform inversion involving reflection phases may also be helpful for further improvement of the reflection profiles (e.g., Sirgue et al. 2010; Shiraishi et al. 2019) with better spatial resolution and reliability of velocities within the thick crust than that by traveltime tomography, especially in the thick crust with the shallow complex fault-fold belt (the eastern side of Figs. 3 and 4). Low-frequency coherent phases observed in the crust (at depths of 10-15 km and the horizontal distances of $140-180 \mathrm{~km}$ in Fig. 3 and $40-180 \mathrm{~km}$ in Fig. 4) are probably remnant artefacts due to multiples or direct waves. Novel methods for signal-to-noise enhancement optimal for sparse OBS data are needed to improve the reflection 

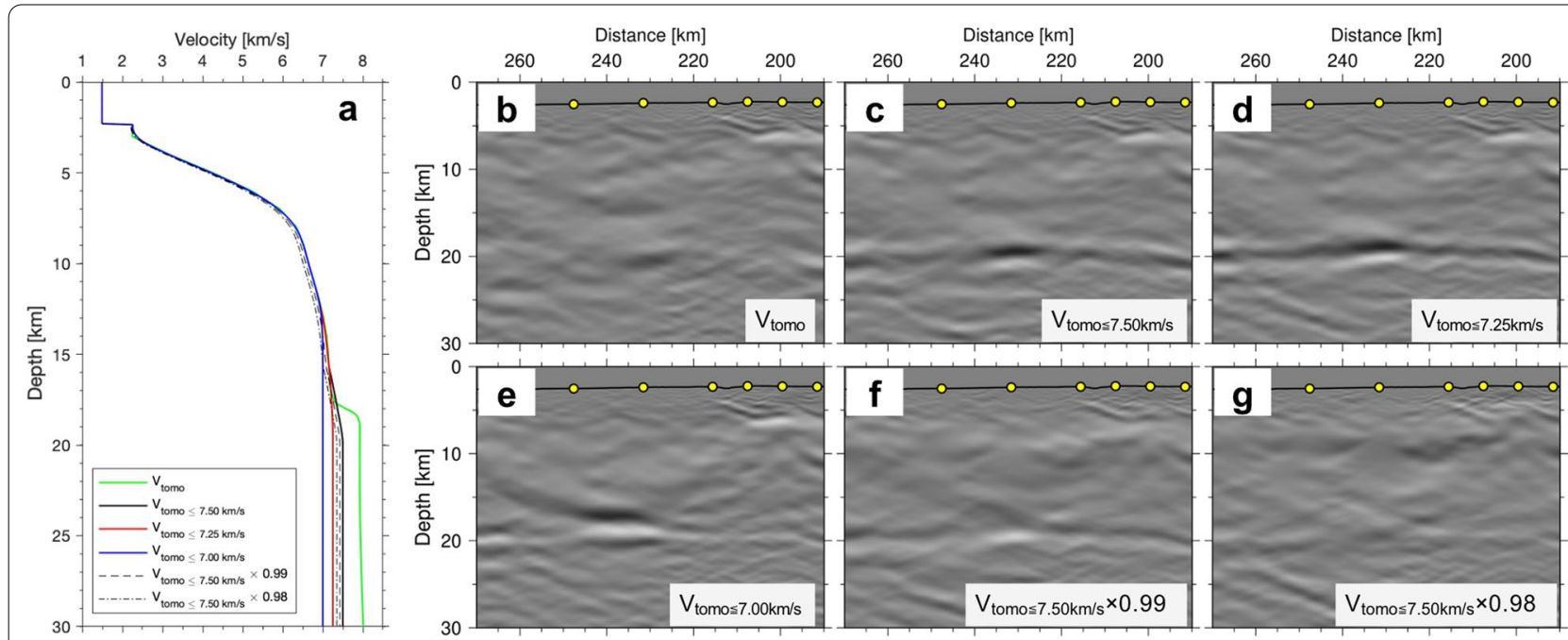

Fig. 5 Comparison of RTM images obtained from different velocity models. a Vertical velocity profiles, which correspond to RTM images in $\mathbf{b}-\mathbf{g}$, at a horizontal distance of $230 \mathrm{~km}$. RTM images from $\mathbf{b}$ the original traveltime tomography result and velocity models limited to $\mathbf{c} 7.5 \mathrm{~km} / \mathrm{s}, \mathbf{d} 7.25 \mathrm{~km} / \mathrm{s}$, and $\mathbf{e} 7.0 \mathrm{~km} / \mathrm{s}$ and scaled by $\mathbf{f} 99 \%$ and $\mathbf{g} 98 \%$ after the upper limit to $7.5 \mathrm{~km} / \mathrm{s}$. The yellow dots indicate OBS locations

images of detailed structures in the crust. However, the spatial resolution of the OBS reflection images is lower than that of the MCS data because the airgun-OBS data generally consist of lower frequency signals than the MCS data due to the decay of high-frequency components during long path wave propagation. Therefore, complementary analysis of the OBS reflection profiles with the high-resolution image of the shallow part by the MCS survey is still important for a comprehensive understanding of crustal structures.

\section{Conclusion}

We successfully imaged the Moho discontinuity at depths of $20-30 \mathrm{~km}$ by the RTM method using reflections observed by offshore wide-angle seismic data with airgun shots and OBSs on the eastern margin of the Sea of Japan. We applied the RTM method to airgun-OBS data with regional velocity models obtained by traveltime tomography from the same datasets, which is a straightforward approach to investigate deep crustal structures using wide-angle seismic data. We confirmed that reflections in the long offset range are more effective in imaging deep structures than MCS surveys with streamer cables of limited length. The reflection profiles from the airgun-OBS data added constraints of the Moho discontinuity to the velocity distribution estimated by traveltime tomography, which visualizes the depth variation corresponding to the transition from thick oceanic crust in the northern Yamato Basin to continental crust in the region towards the coast. Our results from two survey datasets with different OBS spacings of $5 \mathrm{~km}, 8 \mathrm{~km}$ and $16 \mathrm{~km}$ suggest the high potential of RTM-based imaging for a wide variety of applications to wide-angle seismic data in crustal-scale seismic exploration.

\section{Abbreviations}

RTM: Reverse time migration; OBS: Ocean-bottom seismograph; MCS: Multichannel seismic; FD: Finite difference; RMS: Root mean square.

\section{Acknowledgements}

This research was partially supported by Integrated Research Project on Seismic and Tsunami Hazards Around the Sea of Japan' and 'Multidisciplinary research project for construction of fault model in the high strain rate zone' of the Ministry of Education, Culture, Sports, Science and Technology (MEXT), Japan; and the Japan Society for the Promotion of Science (JSPS) KAKENHI Grant-in-Aid for Scientific Research (C) [JP19K04028] to KS. We thank two anonymous reviewers for providing comments that improved the manuscript.

\section{Authors' contributions}

$\mathrm{KS}$ processed the data and wrote the manuscript in discussion with TN and GF. TN acquired the data underlying the study. KS and TN conceived the study, and GF supervised this project. All authors read and approved the final manuscript.

\section{Funding}

The Ministry of Education, Culture, Sports, Science and Technology (MEXT): 'Integrated Research Project on Seismic and Tsunami Hazards Around the Sea of Japan' and 'Multidisciplinary research project for construction of fault model in the high strain rate zone.' The Japan Society for the Promotion of Science (JSPS) KAKENHI Grant-in-Aid for Scientific Research (C) [JP19K04028] to KS.

\section{Availability of data and materials}

The seismic survey data used in this article are available from the JAMSTEC Seismic Survey Database (http://www.jamstec.go.jp/obsmcs_db/e, https://doi. org/10.17596/0002069)

\section{Declarations}

Ethics approval and consent to participate Not applicable. 


\section{Consent for publication}

Not applicable.

\section{Competing interests}

The authors declare that they have no competing interests.

Received: 1 December 2021 Accepted: 31 January 2022

Published online: 11 February 2022

\section{References}

Baysal E, Kosloff DD, Sherwood JWC (1983) Reverse time migration. Geophysics 48:1514-1524. https://doi.org/10.1190/1.1441434

Chang WF, McMechan G (1990) 3D acoustic prestack reverse-time migration. Geophys Prospect 38:737-755. https://doi.org/10.1111/j.1365-2478.1990. tb01872.x

Claerbout JF (1971) Toward a unified theory of reflection mapping. Geophysics 36:467-481. https://doi.org/10.1190/1.1440185

Claerbout JF (1985) Imaging the earth's interior. Blackwell Scientific Publications, Palo Alto

Dessa JX, Operto S, Kodaira S, Nakanishi A, Pascal G, Uhira K, Kaneda Y (2004) Deep seismic imaging of the eastern Nankai trough, Japan, from multifold ocean bottom seismometer data by combined travel time tomography and prestack depth migration. J Geophys Res 109:B02111. https://doi.org/10.1029/2003JB002689

Etgen J, Gray SH, Zhang Y (2009) An overview of depth imaging in exploration geophysics. Geophysics 74:WCA5-WCA17. https://doi.org/10.1190/1. 3223188

Fujie G, Ito A, Kodaira S, Takahashi N, Kaneda Y (2006) Confirming sharp bending of the Pacific plate in the northern Japan trench subduction zone by applying a traveltime mapping method. Phys Earth Planet Inter 157:72-85. https://doi.org/10.1016/j.pepi.2006.03.013

Górszczyk A, Operto S, Malinowski M (2017) Toward a robust workflow for deep crustal imaging by FWI of OBS data: The eastern Nankai Trough revisited. J Geophys Res 122:4601-4630. https://doi.org/10.1002/2016J B013891

Grion S, Exley R, Manin M, Miao XG, Pica A, Wang Y, Granger PY, Ronen S (2007) Mirror imaging of OBS data. First Break 25:37-42. https://doi.org/10.3997/ 1365-2397.2007028

Kamei R, Pratt RG, Tsuji T (2012) Waveform tomography imaging of a megasplay fault system in the seismogenic Nankai subduction zone. Earth Planet Sci Lett 317-318:343-353. https://doi.org/10.1016/j.epsl.2011.10. 042

Korenaga J (2011) Velocity-depth ambiguity and the seismic structure of large igneous provinces: a case study from the Ontong Java Plateau: velocitydepth ambiguity in LIPs crust. Geophys J Int 185:1022-1036. https://doi. org/10.1111/j.1365-246X.2011.04999.X

Liu Y, Chang X, Jin D, He R, Sun H, Zheng Y (2011) Reverse time migration of multiples for subsalt imaging. Geophysics 76:WB209-WB216. https://doi. org/10.1190/geo2010-0312.1

Nakanishi A, Kodaira S, Miura S, Ito A, Sato T, Park JO, Kido Y, Kaneda Y (2008) Detailed structural image around splay-fault branching in the Nankai subduction seismogenic zone: results from a high-density ocean bottom seismic survey. J Geophys Res 113:B03105. https://doi.org/10.1029/2007J B004974

Nakanishi A, Kurashimo E, Tatsumi Y, Yamaguchi H, Miura S, Kodaira S, Obana K, Takahashi N, Tsuru T, Kaneda Y, Iwasaki T, Hirata N (2009) Crustal evolution of the southwestern Kuril Arc, Hokkaido Japan, deduced from seismic velocity and geochemical structure. Tectonophysics 472:105-123. https:// doi.org/10.1016/j.tecto.2008.03.003

Nakanishi A, Takahashi N, Yamamoto Y, Takahashi T, Citak SO, Nakamura T, Obana K, Kodaira S, Kaneda Y (2018) Three-dimensional plate geometry and P-wave velocity models of the subduction zone in SW Japan: Implications for seismogenesis. Geol Soc Am Spec Pap 534:1-18. https://doi. org/10.1130/2018.2534(04)

No T, Sato T, Kodaira S, Ishiyama T, Sato H, Takahashi N, Kaneda Y (2014a) The source fault of the 1983 Nihonkai-Chubu earthquake revealed by seismic imaging. Earth Planet Sci Lett 400:14-25. https://doi.org/10.1016/j.epsl. 2014.05.026
No T, Sato T, Kodaira S, Takahashi N, Ishiyama T, Sato H (2014b) Multichannel seismic reflection survey in the eastern part of the Japan Sea. JAMSTEC Rep Res Dev 19:29-47. https://doi.org/10.5918/jamstecr.19.29

No T, Sato T, Kodaira S, Arai R, Miura S (2018) Multichannel seismic reflection data from the southern part of the Japan Sea. JAMSTEC Rep Res Dev 27:127-141. https://doi.org/10.5918/jamstecr.27.127

No T, Kodaira S, Sato H, Ishiyama T, Sato T, Miura R, Shimomura N, Shiraishi K, Fujie G (2020) Characteristics of crustal structure off Yamagata revealed by seismic survey and relationship with earthquake source faults in the eastern margin of the Japan Sea. The Seismological Society of Japan Fall Meeting S06P-02

Qin Y, Singh SC, Grevemeyer I, Marjanovic M, Buck WR (2020) Discovery of flat seismic reflections in the mantle beneath the young Juan de Fuca Plate. Nat Commun 11:4122. https://doi.org/10.1038/s41467-020-17946-3

Sato T, No T, Kodaira S, Takahashi N, Kaneda Y (2014) Seismic constraints of the formation process on the backarc basin in the southeastern Japan Sea. J Geophys Res-Sol Ea 119:1563-1579. https://doi.org/10.1002/2013JB0106 43

Sato T, No T, Arai R, Miura S, Kodaira S (2020) Transition from continental rift to back-arc basin in the southern Japan Sea deduced from seismic velocity structures. Geophys J Int 221:722-739. https://doi.org/10.1093/gji/ggaa0 06

Shiraishi K, Fujie G, Sato T, Abe S, Asakawa E, Kodaira S (2017) Interferometric OBS imaging for wide-angle seismic data. Geophysics 82:Q39-Q51. https://doi.org/10.1190/geo2016-0482.1

Shiraishi K, Yamada Y, Nibe T (2019) Thermogenic petroleum potential of the Nankai subduction zone, offshore SW Japan. J Petrol Geol 42:417-434. https://doi.org/10.1111/jpg.12744

Sirgue L, Barkved OI, Dellinger J, Etgen J, Albertin U, Kommedal JH (2010) Full waveform inversion: the next leap forward in imaging at Valhall. First Break 28:65-70. https://doi.org/10.3997/1365-2397.2010012

Zelt BC, Talwani M, Zelt CA (1998) Prestack depth migration of dense wideangle seismic data. Tectonophysics 286:193-208. https://doi.org/10.1016/ S0040-1951(97)00265-5

Zhou HW, Hu H, Zou Z, Wo Y, Youn O (2018) Reverse time migration: A prospect of seismic imaging methodology. Earth-Sci Rev 179:207-227. https://doi.org/10.1016/j.earscirev.2018.02.008

\section{Publisher's Note}

Springer Nature remains neutral with regard to jurisdictional claims in published maps and institutional affiliations.

\section{Submit your manuscript to a SpringerOpen ${ }^{\circ}$ journal and benefit from:}

- Convenient online submission

- Rigorous peer review

- Open access: articles freely available online

- High visibility within the field

- Retaining the copyright to your article

Submit your next manuscript at springeropen.com 